\title{
Using the M-Learning to Support Learning of the Concept of the Derivative
}

\author{
Daniel A. Sarmiento, Chadwick Carreto A, Elena F. Ruiz \\ Instituto Politécnico Nacional, School of Computing (ESCOM), \\ Mexico \\ \{dasarmiento, ccarretoa, eruizf $\} @$ ipn.mx
}

\begin{abstract}
One of the main obstacles in Mexico's engineering programs is math comprehension, especially in the Derivative concept. Due to this, we present a study case that relates Mobile Computing and Classroom Learning in the "Escuela Superior de Cómputo", based on the Educational model of the Instituto Politécnico Nacional (competence based work and problem solutions) in which we propose apps and activities to teach the concept of the Derivative. MLearning is emphasized as one of its lines, as the objective is the use of mobile devices running an app that uses its components such as sensors, screen, camera and processing power in classroom work. In this paper, we employed Augmented Reality (ARRoC), based on the good results this technology has had in the field of learning. This proposal was developed using a qualitative research methodology supported by quantitative research. The methodological instruments used on this proposal are: observation, questionnaires, interviews and evaluations. We obtained positive results with a $40 \%$ increase using MLearning, from the $20 \%$ increase using traditional means.
\end{abstract}

Keywords: Augmented reality, classroom learning, educational research, mobile computing.

\section{Introduction}

At the time of writing, there are software programs that have the purpose to help math comprehension. Nevertheless, examining this programs yields that they only develop algebraic and memory competences, leaving aside visualization, comprehension and reasoning in math [1].

One of the major shortcomings of this programs is that they cannot be executed in mobile devices and those that can are have limited features, lacking a teacher's classroom support. Due to the low number of mobile applications that develop different competences and that combine classroom learning and M-Learning [2], we propose the use of mobile computing through an educational application, having as a study case the topic of Derivative corresponding to ESCOM's curricula. 


\section{A. Mobile Computing}

Mobile computing is being developed, explored and use in different countries, because mobile applications allow the student to build their own learning environment with all the necessary resources and tools in a single device. Technology has evolved from simple phones to handheld computers that are capable of browsing the internet, checking email, using location services (GPS) and that have complex sensors such as a multitouch screen, digital compass and accelerometer. Mobile software has also evolved to a point that resembles desktop operating systems.

\section{B. Instituto Politécnico Nacional's Educational Model}

The Polytechnic Institute's Educational Model promotes an integral, high quality formation, that's oriented towards the student's learning. To achieve this, it is necessary to have flexible programs that incorporate the possibility of transit between modalities, programs, levels, academic units and the diversification of learning spaces. It is also necessary to introduce teaching methodologies that prioritize innovation, creative capacity and the use of Information and Communication Technologies.

\section{Mobile Learning}

Mobile devices applied to educational environments are an innovative alternative that can potentially help improving teaching-learning processes [10]. We denominate the intersection between online education and mobile computational devices as Mobile Learning [2]. It offers advantages such as frequent and integral access to applications that support learning anytime anywhere. In other words, mobile learning can be seen as the use of mobile devices in the learning process.

\section{Augmented Reality}

Augmented Reality is the term used to define a direct or indirect vision of a physical environment of the real world, in which its elements are combined with virtual elements to create a mixed reality in real time $[11,12]$.

Augmented reality is made of a real scene, which is obtained in real time using a device's camera and the additional information associated to that scene. The fusion of both elements is made using a mobile device's computing power to show a single image on the screen. The use of such technologies in a school must be framed by its educational model, so that they can be easily used in classrooms.

\section{Objectives}

As we mentioned before, the main problem lies in using applications that develop a range of competences in the student with a model that promotes the use of Information and Communication Technologies. Thus, we have the following main objective:

Evaluate the combination of mobile computing and classroom learning on the Derivative case study as an education support tool. From this main objective we derive the following secondary objectives:

- Determine the relevance of using Mobile Computing and classroom learning. 
- Stablish Mobile Computing activities and apps that support learning the Derivative concept.

- Verify the efficiency of mobile computing combined with classroom learning.

\section{Methodological Aspects}

Our object of study are students of the first semester in the "Escuela Superior de Cómputo", given that the Calculus Learning Unit, which contains the Derivative as one of its topics, is taught on that semester. It is important to emphasize that the qualitative approach helps document and analyze the processes that use Mobile Computing [1]. This approach must be based on a qualitative research in which we assume that the meaning of concepts and processes development are socially built in practice [13]. It is also necessary to select a sample, which allows us to conduct the study in an efficient way. Thus, the research methodology used is of a mixed character, because we employed a qualitative methodology that gathers data without numerical measurement and a qualitative to represent the results. The instruments we used are:

- Observation.

- Questionnaires.

- Interviews.

- Evaluation of the obtained results.

The instruments above are used throughout the research and will be described on the "Case Study" section. The proposed stages of proposed research methodologies, instruments and teaching methodology are executed in parallel. We then propose the following stages for the research methodology:

1. Perform diagnostic evaluations and surveys to the study group.

2. Analyze the Learning Unit's activities.

3. Develop classroom and mobile learning activities.

4. Gather and analyze the activities' results.

The stages for the methodological instruments are as follow:

1. Select data instruments such as observation, questionnaires, surveys, interviews and study subject.

2. Analyze the functionality of the data gathering instruments to select the software methodology.

3. Carry out the Software Engineering process.

4. Analyze the results obtained by the Software Engineering methodology.

The teaching methodology is divided in three: materials, resources and results and subdivided in the following stages.

Materials and resources stages:

1. Select materials such as pencils, paper sheets, notebooks, blackboard and mobile devise.

2. Use mobile devices on the study group.

3. Analyze the resources needed to deploy a server or platform if necessary. 
4. Analyze the total budget spent in resources and materials.

Results stages:

1. Results given by school statistics and activities' requirements.

2. Results given by activities in classroom and using mobile devices.

3. Recollecting the total results given by the previous phases.

4. Answering the research questions and validating the research hypothesis.

\section{A. Survey on Mobile Devices}

We employed a predesigned survey as a methodological instrument and observational study that allows the researcher to gather data without modifying the environment nor controlling the observed process. The data was obtained using a set of normalized questions directed towards a representative sample of the case study, which is composed by ESCOM's students [1].

A closed survey was selected due to it being of uniform character and easier to quantify. In this kind of survey both, study group A and study group B select just one of the options given from a list of possibilities.

The questions and answers were previously formulated by the researcher, thus allowing to obtain the needed information.

\section{B. Diagnostic questionnaire}

A diagnostic questionnaire as a methodological instrument is useful in gathering data and as a starting point for the use of qualitative methods [14, 15]

A questionnaire must be clear, unambiguous and uniformly accomplishable. In this case, the diagnostic questionnaire was made of ten questions related to the Calculus Learning Unit, specifically to the Derivative concepts. These questionnaires were previously validated $[16,17]$. We selected two study groups, denominated A and B, in which former had high academic performance and the latter had an average performance.

Each question was classified as algorithmic or concept related.

- Algorithmic questions are those in which the student must know the method or the steps needed to solve the questions and are only asked to calculate or find a result.

- Concept related questions imply that the student understands the concept involved so that he/she can find the correct answer.

The activities that were performed in group A and B were designed based on the questions of the diagnostic questionnaires. For this purpose, we selected the questions with a higher rate of failure, which were the ones that asked them to calculate the slope of a tangent line and the rate of change.

\section{Activity 1. Derivate concept}

Figure 2 shows the definition of the derivative as a tangent line to a curve [18], then it describes its purpose.

\section{Application 1. SENSORTAG}


The SensorTag activity was designed to get the inclination angle of a slope using the mobile device's sensors. The survey we performed showed that $97.9 \%$ of the mobile devices use by both study group A and B had the capability to run this activity. Figure 3 shows one of the views of the SensorTag App.

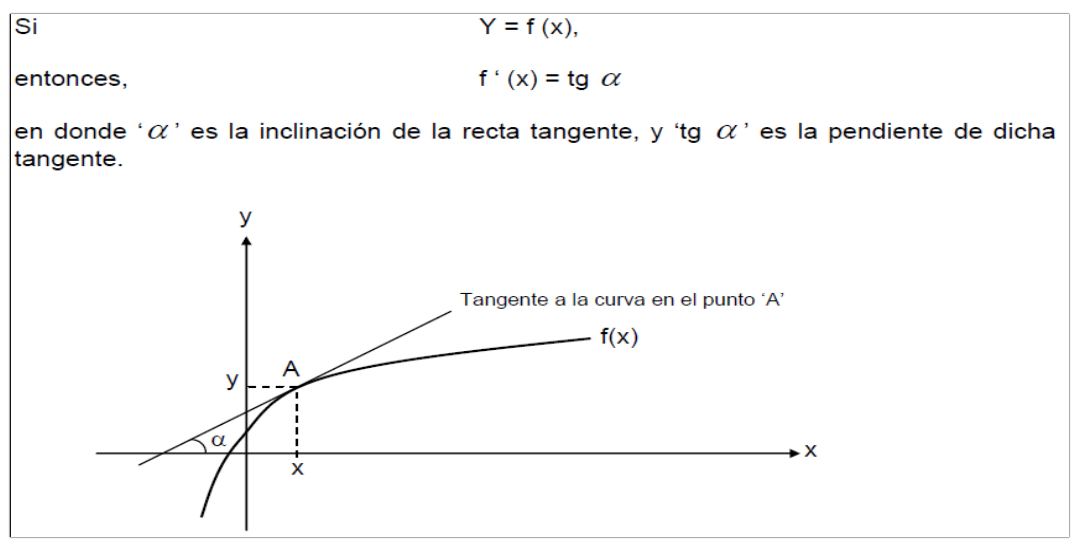

Fig. 2. Geometrical definition of a derivative.

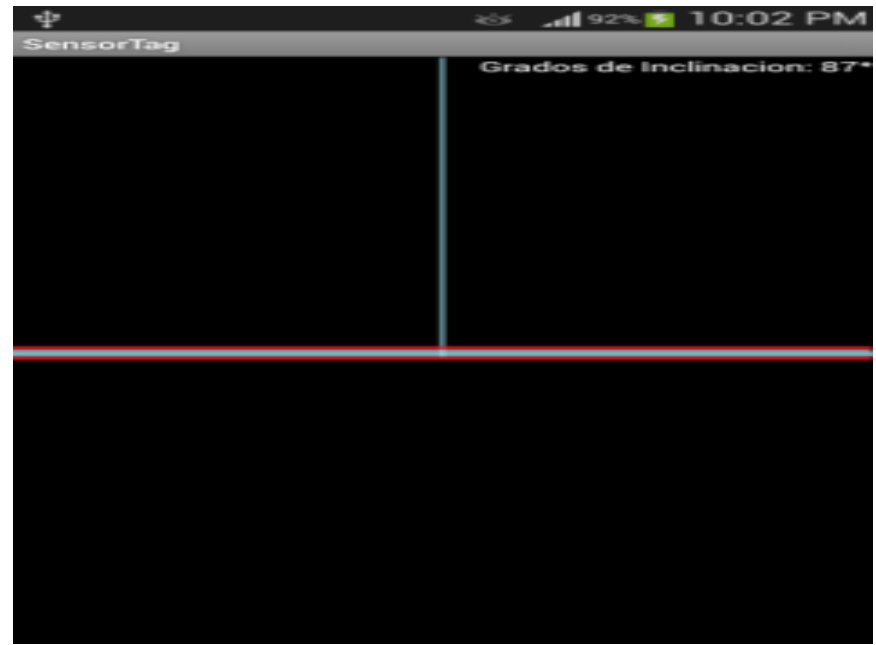

Fig. 3. SensorTag activity.

E. Activity 2. Rate of Change

Figure 4 shows an example in which the rate of change concept is applied.

Purpose: We wish to determine if the student comprehends the concept of the rate of change, using an example in which an Android shaped balloon loses gas, radius and surface as time goes by.

F. Application 2. ARRoC 
The ARRoC activity was designed so that group A and B could see in the classroom what happens in real time to an object that suffers a variation in an instant, which is known as rate of change and can be obtained using the derivative.

El gas de un globo esférico en forma de Android se escapa a razón de $1,000 \mathrm{~cm} 3 / \mathrm{min}$ en el mismo instante en que el radio es de $25 \mathrm{~cm}$. a) ¿Con qué rapidez disminuye el radio?

b) ¿Con qué rapidez disminuye el área de la superficie?

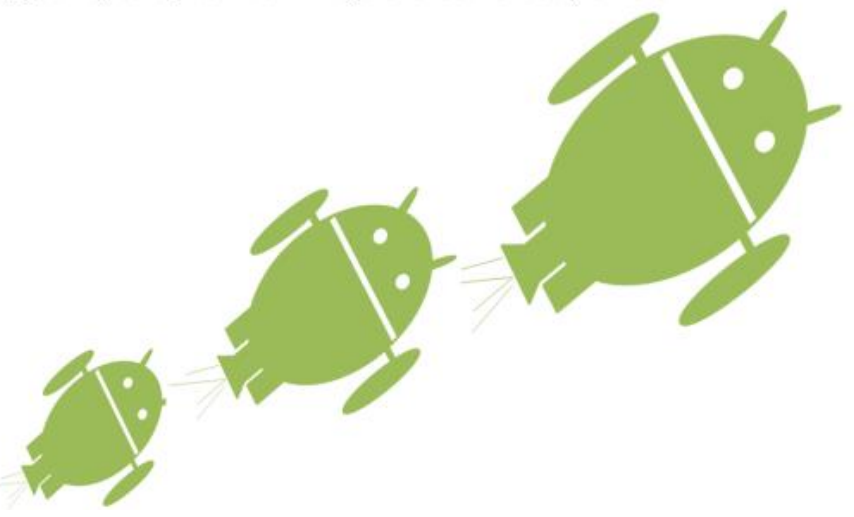

Fig. 4. Rate of change example.

This activity uses the mobile device's camera and an augmented reality marker, which allows to visualize the object. Figure 5 shows a screenshot of the running app.

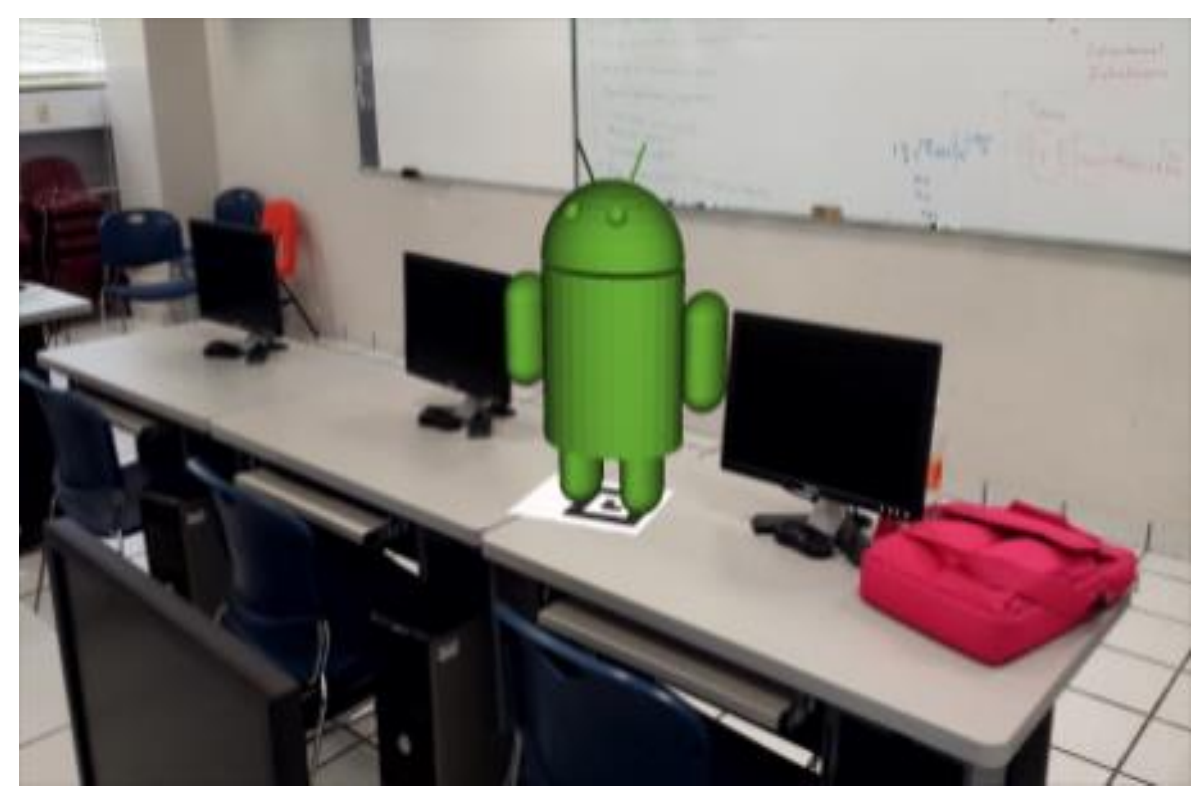

Fig. 5. ARRoC visualization. 


\section{Results}

The surveys conducted in ESCOM show that $80 \%$ of the students possess a smartphone, which has a great computing power. The specifications of this mobile devices allow us to take advantage of the similarities between how the students use their mobile devices and the National Polythecnic Institute's Educational Model.

It is also worth mentioning that when the teacher made the application available to the students, they showed interest in using their smartphone and had better grasp of the derivative concept.

The results obtained by study group A, showed that the students had an acceptable performance, responding well in an overall way. The same phenomenon was observe in study group B, which had an excellent performance in the evaluation questionnaire as they all passed it. This results are of great importance, because they show the difference between the diagnostic questionnaire in which just a minimum amount of students had an approbatory grade.

Tables 1 and 2 show each question's results divided by each study group.

Table 1. Results of study group A.

\begin{tabular}{lcc}
\hline \multicolumn{1}{c}{ SensorTag Application Questions } & Questions & $\begin{array}{c}\text { Correct } \\
\text { percentage }\end{array}$ \\
\hline $\begin{array}{l}\text { How should the derivative of a function be when the } \\
\text { tangent line has a positive slope? }\end{array}$ & 1 & $87 \%$ \\
$\begin{array}{l}\text { How should the derivative of a function be when the } \\
\text { tangent line has a negative slope? }\end{array}$ & 2 & $87 \%$ \\
$\begin{array}{l}\text { How should the derivative of a function be when the } \\
\text { tangent line has a value of 0? }\end{array}$ & 3 & $83 \%$ \\
$\begin{array}{l}\text { What can we obtain when the derivative of the slope } \\
\text { has a value of 0? }\end{array}$ & 4 & $100 \%$ \\
$\begin{array}{l}\text { ARRoC Application Questions } \\
\text { How fast does the radius of the android's arms } \\
\text { decrease? }\end{array}$ & 1 & $100 \%$ \\
$\begin{array}{l}\text { How fast does the area decrease on the surface of the } \\
\text { android's arms? }\end{array}$ & 2 & $83 \%$ \\
\hline
\end{tabular}

Table 2. Results of study group B.

\begin{tabular}{lcc}
\hline \multicolumn{1}{c}{ SensorTag Application Questions } & Questions & $\begin{array}{c}\text { Correct } \\
\text { percentage }\end{array}$ \\
\hline $\begin{array}{l}\text { How should the derivative of a function be when the } \\
\text { tangent line has a positive slope? }\end{array}$ & 1 & $93 \%$ \\
$\begin{array}{l}\text { How should the derivative of a function be when the } \\
\text { tangent line has a negative slope? }\end{array}$ & 2 & $94 \%$ \\
$\begin{array}{l}\text { How should the derivative of a function be when the } \\
\text { tangent line has a value of 0? }\end{array}$ & 3 & $88 \%$ \\
$\begin{array}{l}\text { What can we obtain when the derivative of the slope } \\
\text { has a value of 0? }\end{array}$ & 4 & $100 \%$
\end{tabular}




\begin{tabular}{lcc}
\multicolumn{1}{c}{ ARRoC Application Questions } & Questions & $\begin{array}{c}\text { Correct } \\
\text { percentage }\end{array}$ \\
$\begin{array}{l}\text { How fast does the radius of the android's arms } \\
\text { decrease? }\end{array}$ & 1 & $100 \%$ \\
$\begin{array}{l}\text { How fast does the area decrease on the surface of the } \\
\text { android's arms? }\end{array}$ & 2 & $86 \%$ \\
\hline
\end{tabular}

\section{Discussion}

Mobile computing is the best tool for the student to visualize situations where the derivative concept is present. Even though a graphing calculator could be use, it's more feasible to use a mobile device, since most students already possess one and a mobile device has more features like internet capabilities, sensors and a camera; which help out the student during his/her lessons.

\section{Conclusion}

After examining the developed applications and activities in this research, we observed that Mobile Computing is present at all times in all places.

We determined the specifications of the mobile devices owned by the case study students and we conclude that Mobile computing and classroom learning is relevant in the Derivative learning process.

Working with a qualitative methodology supported by quantitative aspects helped us have a better vision of what happened during work sessions, prioritizing observation, which helped us validate the development of this research. The Mobile Computing's activities, were designed and implemented. This activities helped the students learn the Derivative concept by allowing the development of competences such as the ability to visualize phenomena, reflection capacity and problem solving abilities.

This allowed us to find a relationship between mobile Computing and Educational Mathematics, emphasizing aspects that are outlined in the National Polytechnic Institute's educational model. Using mobile computing, students could transition from concrete concepts to abstract concepts, generating tangible products, which allowed them to have a clear idea of the concepts given to them in the case study.

After analyzing the combination of Mobile Computing and Classroom Learning we conclude that Mobile computing is a valuable tool in supporting the teaching process, as showed by the $40 \%$ increase in the topic understanding, opposed to the $20 \%$ average increase by using traditional means. This result proves that the research hypothesis was correct. Using mobile computing in the classroom allows decreasing mechanical solutions to problems, visualizing and proposing solutions, and motivates students to use their mobile devices as information capturing devices; helping them process information and thus, reaching valid conclusions.

Finally, we observed that mobile devices are replacing calculators and computers in classrooms, with the clear advantage of portability and real time information capturing. 
Acknowledgment. We want to thank Secretaría de Investigación y Posgrado (SIP) of the Instituto Politécnico Nacional for the support during this work, project 20150296.

\section{References}

1 Hérnandez Sampieri, R., Fernández Collado, C., P. Baptista, L.: Metodología de la Investigación. McGraw-Hill, México, pp. 350-500 (2008)

2 Potts, J., Moore, N., Sukittanon, S.: Developing Mobile Learning Applications for Electrical Engineering Courses. University of Tennessee at Martin, Department of Engineering, TN. U.S.A., pp. 2-6 (2011)

3 Secretaría Académica, Instituto Politécnico Nacional IPN, Dirección de Educación Superior, Escuela Superior de Cómputo (ESCOM): Programa Sintético, Plan 2009 Unidad de Aprendizaje de Cálculo. http://148.204.58.221/DISC/temarios/ plan2009/NIVEL2/Calculo.pdf. 21 de Noviembre de 2013 (2009)

4 Secretaria de Educación Pública. Instituto Politécnico Nacional. Mapa Curricular ESCOM, http://www.escom.ipn.mx/Oferta/Paginas/mapacurricular.aspx (2013)

5 MacOS. Apple Developers. Desarrolladores de Apps, https://developer.apple.com/ (2013)

6 Nestel, D., Ng, A., Grey, K., Hill, R., Villanueva, E., Kotsanas, G., Oaten, A., Browne, C.: Evaluation of Mobile Learning: Students Experiences in a New RuralBased Medical School, BMC Medical Education, http://www.biomedcentral. com/1472-6920/10/57 (2010)

7 Google. Android Developers. Desarrolladores de Aplicaciones. http://developer.android.com/index.html (2013)

8 MacOS, Apple Developers. Herramienta de Desarrollo IDE. https://developer. apple.com/xcode/ (2013)

9 Instituto Politécnico Nacional. Materiales para la Reforma: Un Nuevo Modelo Educativo para el IPN. Talleres Gráficos de la Dirección de Publicaciones del Instituto Politécnico Nacional, D.F., México, P18 (2004)

10 Johnson, L., Adams. B., Cummins, S., Estrada, M., Freeman, V., Ludgate, A.: Higher Education Edition 2013. Austin. Texas: The New Media Consortium, pp. 2-15 (2013)

11 Raghav, S.: Pro Android Augmented Reality, New York, Apress, pp. 1-150 (2012)

12 Ariel y Fundación Telefónica con colaboración del Banco Interamericano de Desarrollo. Realidad Aumentada un Nuevo Lente para Ver el Mundo. Ariel ed. Madrid, España, pp. 22-80 (2011)

13 Moschkovich, J., Brenner, M.: Integrating a Naturalistic Paradigm into Research on Mathematics and Science Cognition and Learning. In: Handbook of Research Design in Mathematics and Science Education, Erlbaum Associates Inc., pp. 457486 (2000)

14 Valdemoros Álvarez, M.E.: La Constancia de la Unidad en la Suma de Fracciones: Estudio de Caso. Investigaciones en Matemática Educativa II, pp. 465-481 (1998)

15 Valdemoros Álvarez, M.E.: Recursos Intuitivos que Favorecen la Adición de Fracciones: Estudio de Caso. Educación Matemática, pp. 5-17 (1997) 
16 Gutiérrez G., J.J.: Sistema Móvil como Herramienta de Apoyo para el Aprendizaje de Cálculo. Caso de Estudio Funciones. Tesis, Escuela Superior de Cómputo (ESCOM), IPN, México DF, México, pp. 8-110 (2013)

17 Viveros, K.: Continuidad y la Derivada de una Función: Concepciones y Conexiones Intuitivas en Estudiantes Universitarios. Tesis, CINVESTAV-IPN, México DF, pp. 65-90 (2001)

18 Jame, S.: Aplicación de la Derivada en Cálculo. Thomson Learning, México, pp. 276-279 (2002) 